\title{
BASIC ALLOY DESIGN CONCEPTS AND STEELMAKING/CASTING CONSIDERATIONS FOR OPTIMIZED HOT STRIP STRUCTURAL STEEL IN YIELD STRENGTHS FROM 300 - 700 MPA*
}

Douglas Glenn Stalheim 1 Danilo Di Napoli Guzela² Antonio Augusto Gorni ${ }^{3}$

\begin{abstract}
Production of structural hot strip coils in yield strengths up to $700 \mathrm{MPa}$ and higher is increasing worldwide. In addition to requiring higher strengths, structural designs require good formability, toughness and weldability. Toughness and formability come from optimization of ductility properties while weldability comes from lower carbon equivalent alloy designs. The key to the production of optimized cost effective hot strip produced structural coils is to create the correct balance of a proper alloy/processing design to create as fine and uniformly distributed cross sectional grain size as possible. In addition to the creation of the fine/uniformly distributed cross sectional grain size, the correct microstructure needs to be created. In the higher yield strength grades, not only does the grain size/distribution play a role but a proper understanding and control of microalloying precipitation kinetics is required. This paper will present various examples of hot strip alloy designs to produce cost effective hot strip structural coil in yield strengths up to $700 \mathrm{MPa}$ with good ductility and weldability. In addition, steelmaking/casting parameters will be discussed to assure successful production. Optimized reheating, rolling and cooling parameters of these alloy designs will be introduced in an accompanying paper.
\end{abstract}

Keywords: Microalloy; Niobium; Casting; Parameters.

1 Bachelor of Science in Metallurgical Engineering, South Dakota School of Mines and Technology, USA, President, DGS Metallurgical Solutions, Inc., Vancouver, WA USA.

Metallurgist Engineer, Consultant, CBMM, São Paulo, SP, Brasil.

Materials Engineer, M. Eng., Dr. Eng., Technical Editor, Aranda Editora, São Paulo, SP, Brasil, 


\section{INTRODUCTION}

Production of cost effective hot rolled structural steel coils with desired strength and ductility properties along with excellent weldability is the trend in today's structural steel market. Cost effectiveness means that the alloy/process design needs to be optimized to minimize production costs, but also robust enough to easily meet the mechanical property requirements within a statistical normal distribution to avoid costly downgrades, rejections and replacement material. The ability to achieve an overall cost effective structural steel coil requires knowledge of how to properly design the alloy, process, implement the design and then control the process to achieve the stable mechanical properties that create a statistical normal distribution of performance. This design starts with an understanding of what would be the desired microstructure for the requirements along with the desired cross sectional grain size/distribution which then translate into an alloy/process design. Once the alloy/process design is determined implementation and process control of the design are required to achieve the desired results. When this is properly done, a hot strip structural steel coil can be produced that can be technically marketed as an optimum cost effective solution in the market place. This paper will be first of two papers that will give general guidance on microstructure, grain size/distribution, alloy/process design, processing controls through steelmaking and casting. The second paper will address reheating, rolling and cooling design/process control to implement the alloy designs presented.

\section{MICROSTRUCTURE/GRAIN SIZE DESIGN}

\subsection{Microstructure}

Hot rolled structural steel coils are a mix of various volume fractions of microstructural phases. The major volume fraction microstructural phase typically is polygonal ferrite. This is followed by a smaller secondary phase of either pearlite, upper bainite or acicular ferrite depending on final actual chemistry along with the desired strength, toughness and formability. Generally a polygonal ferrite/pearlite/upper bainite microstructure by volume fraction in properly designed hot strip structural steel would range from $80-95 \%$ polygonal ferrite and $5-20 \%$ pearlite/upper bainite If high yield strength, $>550 \mathrm{MPa}$, along with any combination of formability, such as the hole expansion test, and/or lower temperature toughness of $20^{\circ} \mathrm{C}$ or lower, then the desired secondary phase would be acicular ferrite. Acicular ferrite is a low carbon $(<0.08 \%)$ form of bainite that not only contributes to strength but also has excellent toughness and formability characteristics. In these higher strength steels the volume fraction of microstructural phases typically will range from $70-95 \%$ polygonal ferrite and $5-30 \%$ acicular ferrite depending on alloy design and post rolling cooling strategy.

\subsection{Grain Size/Distribution}

The largest contribution to strength and toughness comes from the average cross sectional grain size and the uniformity/distribution of those grains through the cross section. In particular average cross sectional grain size equals strength and the uniformity/distribution cross sectional grain size equals ductility (toughness, elongation and formability) [1]. In addition, the final microstructure and shape/flatness 
control of the strip is heavily influenced by the cross sectional uniformity/distribution of the grains. In regard to strength, $40-70 \%$ of all the strength for a given microstructure in a structural steel comes from the grain size. Figure 1 shows the contribution of grain size on strength along with an example of a comparison of average and distribution of grain size vs. charpy toughness performance $[2,3]$.
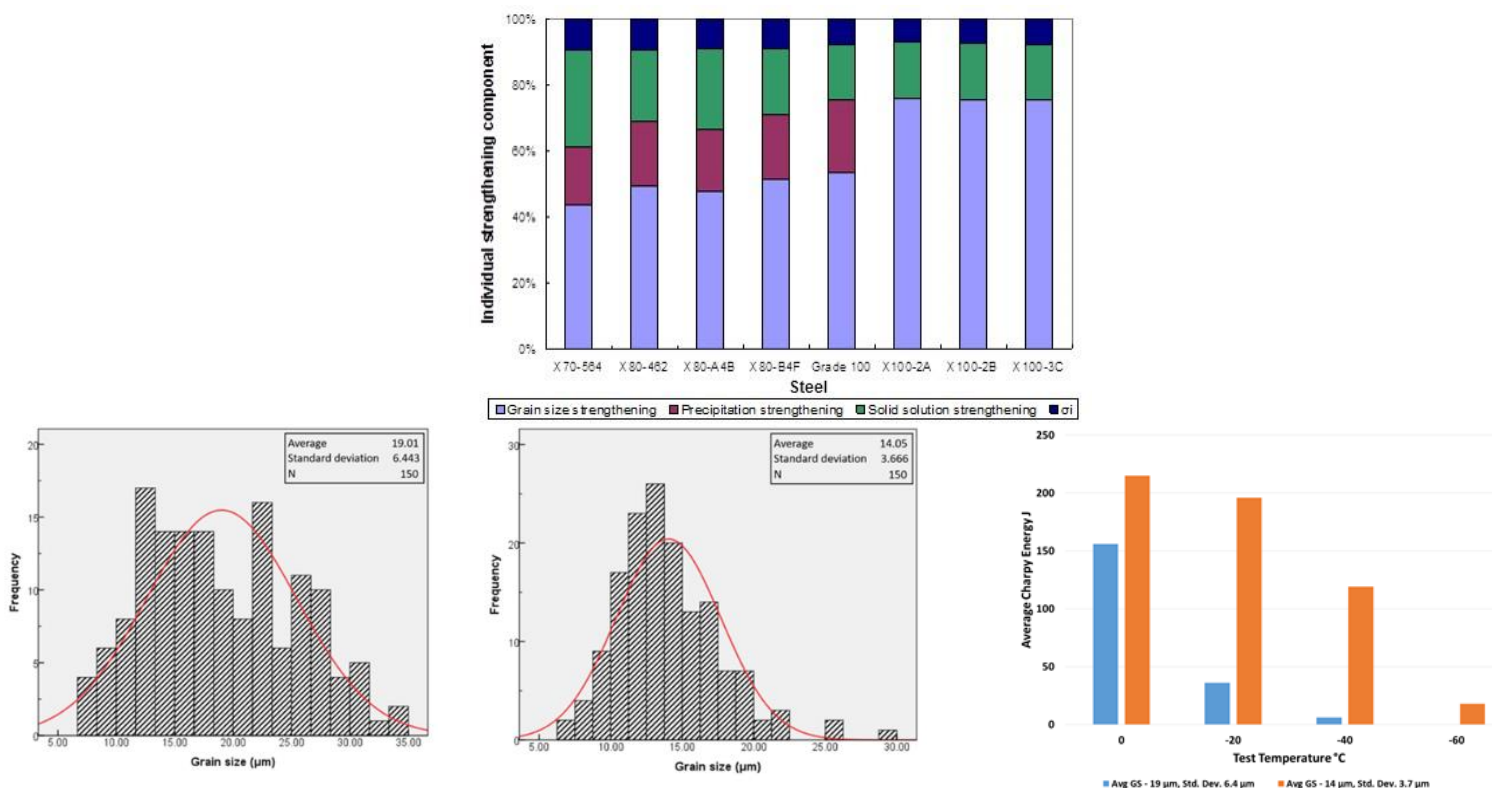

Figure 1. Top graph shows the contribution of grain size toward strength (blue shading), bottom row shows the effect of average grain size AND grain size distribution on charpy toughness performance.

To optimize the cross sectional grain size correct design of the alloy/process is needed to create the proper amount of the two key recrystallization behaviors, Type I Static Recrystallization and Type II No-recrystallization [4,5]. This will be discussed in more detail in the second paper on reheating, rolling and cooling.

\section{ALLOY DESIGN}

Creating the optimum alloy design for a cost effective hot strip coil with stable mechanical properties with a statistically normal distribution of mechanical properties and good weldability requires a balance of some key elements as follows:

- Carbon - $<0.10 \%$ for weldability, ductility and formation of acicular ferrite microstructure as needed.

- Manganese - will be the main solute strengthening element which can range from $0.40-1.90 \%$. Note that $\mathrm{Mn}$ is for strength only.

- Niobium - Nb along with processing is what will drive the volume percentage of Type II No-recrystallization. The lower strength/no toughness grades will require less $\mathrm{Nb}$, but as strength, thickness and toughness requirements increase the amount of $\mathrm{Nb}$ required also increases. This is what will drive how much Type II recrystallization behavior that can be created and hence the final cross sectional average grain size and distribution/uniformity.

- Titanium - is used in two roles in these steels, one is to tie up the N2 which improves $\mathrm{Nb}$ efficiency and in higher strength grades contributes to strengthening through interphase and random precipitation during post rolling cooling. Depending on what role the Ti is playing determines the amount.

- Silicon - is typically $<0.05 \%$, but can be increased to $0.30 \%$ for strength. 
- Aluminum - does not contribute to the final mechanical properties and in general just creates inclusions that adversely affect ductility. Therefore it should be kept as low as possible to properly "kill" the oxygen activity and meet a societal standard.

- Copper, Nickel, Chromium, Molybdenum and Vanadium - can be added if needed to enhance strength and/or microstructure. In general they are not required for most structural steels.

- Phosphorus and Sulfur - should be kept reasonable.

Table 1 shows a cost effective general alloy design for various strengths, toughness in two thickness ranges for hot strip coil.

Table 1. Cost effective alloy design guidelines

\begin{tabular}{|c|c|c|c|c|c|c|c|c|c|c|c|c|c|c|c|c|c|c|c|c|}
\hline \multirow{2}{*}{$\begin{array}{c}\text { Transverse Yield } \\
\text { Strength Range } \\
\text { (Mpa) }\end{array}$} & \multirow{2}{*}{$\begin{array}{c}\text { Transverse } \\
\text { Tensile Strength } \\
\text { Range (Mpa) }\end{array}$} & \multirow{2}{*}{$\begin{array}{c}\text { Charpy } \\
\text { Requirment } \\
\left({ }^{\circ} \mathrm{C}\right)\end{array}$} & \multicolumn{2}{|c|}{ Thickness Range (mm) } & \multirow[t]{2}{*}{ c } & \multirow[t]{2}{*}{$\mathrm{Mn}^{(10)}$} & \multirow[t]{2}{*}{$\mathbf{P}$} & \multirow[t]{2}{*}{$S$} & \multirow[t]{2}{*}{$\mathrm{Si}^{(1)}$} & \multirow[t]{2}{*}{$\mathrm{Cu}$} & \multirow[t]{2}{*}{$\mathrm{Ni}$} & \multirow[t]{2}{*}{$\mathrm{Cr}$} & \multirow[t]{2}{*}{ Mo } & \multirow[t]{2}{*}{ v } & \multirow[t]{2}{*}{$\mathrm{Nb}^{(7)}$} & \multirow[t]{2}{*}{ Alt } & \multirow[t]{2}{*}{$\mathrm{Ti}$} & \multirow[t]{2}{*}{$\mathrm{N} 2^{(2)}$} & \multirow[t]{2}{*}{$\mathrm{CE}^{12,13}$} & \multirow[t]{2}{*}{$\mathrm{Pcm}^{12,14}$} \\
\hline & & & Min & Max & & & & & & & & & & & & & & & & \\
\hline $300-400$ & $420-520$ & No & 3 & 8 & $0.05-0.09$ & $0.40-0.60$ & $<0.018$ & $<0.010$ & $<0.05$ & Res & Res & Res & Res & Res & $0.015-0.020$ & $<0.030$ & $\operatorname{Res}^{(3)}$ & $<100 \mathrm{ppm}$ & $0.13-0.20$ & $0.07-0.12$ \\
\hline $300-400$ & $420-520$ & No & 8 & 16 & $0.05-0.09$ & $0.40-0.60$ & $<0.018$ & $<0.010$ & $<0.05$ & Res & Res & Res & Res & Res & $0.020-0.030$ & $<0.030$ & $\operatorname{Res}^{(3)}$ & $<100 \mathrm{ppm}$ & $0.13-0.20$ & $0.07-0.12$ \\
\hline $300-400$ & $420-520$ & -20 & 3 & 8 & $0.05-0.09$ & $0.40-0.60$ & $<0.018$ & $<0.010$ & $<0.05$ & Res & Res & Res & Res & Res & $0.020-0.030$ & $<0.030$ & $\operatorname{Res}^{(3)}$ & $<100 \mathrm{ppm}$ & $0.13-0.20$ & $0.07-0.12$ \\
\hline $300-400$ & $420-520$ & -20 & 8 & 16 & $0.05-0.09$ & $0.40-0.60$ & $<0.018$ & $<0.010$ & $<0.05$ & Res & Res & Res & Res & Res & $0.020-0.030$ & $<0.030$ & $\operatorname{Res}^{(3)}$ & $<100 \mathrm{ppm}$ & $0.13-0.20$ & $0.07-0.12$ \\
\hline $400-500$ & $520-620$ & No & 3 & 8 & $0.05-0.09$ & $0.80-1.30$ & $<0.018$ & $<0.010$ & $<0.05$ & Res & Res & Res & Res & $\operatorname{Res}^{(11)}$ & $0.020-0.030$ & $<0.030$ & $\operatorname{Res}^{(3)}$ & $<100 \mathrm{ppm}$ & $0.19-0.32$ & $0.09-0.16$ \\
\hline $400-500$ & $520-620$ & No & 8 & 16 & $0.05-0.09$ & $0.80-1.30$ & $<0.018$ & $<0.010$ & $<0.05$ & Res & Res & Res & Res & $\operatorname{Res}^{(11)}$ & $0.025-0.035^{(9)}$ & $<0.030$ & $\operatorname{Res}^{(3)}$ & $<100 \mathrm{ppm}$ & $0.19-0.32$ & $0.09-0.16$ \\
\hline $400-500$ & $520-620$ & -20 & 3 & 8 & $0.05-0.09$ & $0.80-1.30$ & $<0.018$ & $<0.010$ & $<0.05$ & Res & Res & Res & Res & $\operatorname{Res}^{(11)}$ & $0.025-0.035^{(9)}$ & $<0.030$ & $\operatorname{Res}^{(3)}$ & $<100 \mathrm{ppm}$ & $0.19-0.32$ & $0.09-0.16$ \\
\hline $400-500$ & $520-620$ & -20 & 8 & 16 & $0.05-0.09$ & $0.80-1.30$ & $<0.018$ & $<0.010$ & $<0.05$ & Res & Res & Res & Res & $\operatorname{Res}^{(11)}$ & $0.025-0.035^{(9)}$ & $<0.030$ & $\operatorname{Res}^{(3)}$ & $<100 \mathrm{ppm}$ & $0.19-0.32$ & $0.09-0.16$ \\
\hline $500-600$ & $620-720$ & No & 3 & 8 & $0.05-0.09$ & $1.30-1.70$ & $<0.018$ & $<0.010$ & $<0.05$ & Res & Res & Res & Res & $\operatorname{Res}^{(11)}$ & $0.030-0.040$ & $<0.030$ & $0.010-0.025^{(4)}$ & $<100 \mathrm{ppm}$ & $0.28-0.38$ & $0.12-0.18$ \\
\hline $500-600$ & $620-720$ & No & 8 & 16 & $0.05-0.09$ & $1.30-1.70$ & $<0.018$ & $<0.010$ & $<0.05$ & Res & Res & Res & Res & $\operatorname{Res}^{(11)}$ & $0.040-0.050^{(9)}$ & $<0.030$ & $0.010-0.025^{(4)}$ & $<100 \mathrm{ppm}$ & $0.28-0.38$ & $0.12-0.18$ \\
\hline $500-600$ & $620-720$ & -20 & 3 & 8 & $0.05-0.09$ & $1.30-1.70$ & $<0.018$ & $<0.010$ & $<0.05$ & Res & Res & Res & Res & $\operatorname{Res}^{(11)}$ & $0.040-0.050^{(9)}$ & $<0.030$ & $0.010-0.025^{(4)}$ & $<100 \mathrm{ppm}$ & $0.28-0.38$ & $0.12-0.18$ \\
\hline $500-600$ & $620-720$ & -20 & 8 & 16 & $0.05-0.09$ & $1.30-1.70$ & $<0.018$ & $<0.010$ & $<0.05$ & Res & Res & Res & Res & $\operatorname{Res}^{(11)}$ & $0.040-0.050^{(9)}$ & $<0.030$ & $0.010-0.025^{(4)}$ & $<100 \mathrm{ppm}$ & $0.28-0.38$ & $0.12-0.18$ \\
\hline $600-700$ & $720-820$ & No & 3 & 6 & $0.05-0.09$ & $1.50-1.90$ & $<0.018$ & $<0.010$ & $<0.05$ & Res & Res & Res & Res & Res & $0.060-0.070$ & $<0.030$ & $0.070-0.090^{(8)}$ & $<100 \mathrm{ppm}$ & $0.31-0.42$ & $0.13-0.19$ \\
\hline $600-700$ & $720-820$ & No & 6 & 12 & $0.05-0.09$ & $1.50-1.90$ & $<0.018$ & $<0.010$ & $<0.05$ & Res & Res & Res & Res & Res & $0.060-0.070$ & $<0.030$ & $0.070-0.090^{(8)}$ & $<100 \mathrm{ppm}$ & $0.31-0.42$ & $0.13-0.19$ \\
\hline $600-700$ & $720-820$ & -20 & 3 & 6 & $0.05-0.09$ & $1.50-1.90$ & $<0.018$ & $<0.010$ & $<0.05$ & Res & Res & Res & Res & Res & $0.060-0.070$ & $<0.030$ & $0.070-0.090^{(8)}$ & $<100 \mathrm{ppm}$ & $0.31-0.42$ & $0.13-0.19$ \\
\hline $600-700$ & $720-820$ & -20 & 6 & 12 & $0.05-0.09$ & $1.50-1.90$ & $<0.018$ & $<0.010$ & $<0.05$ & Res & Res & Res & Res & Res & $0.060-0.070$ & $<0.030$ & $0.070-0.090^{(8)}$ & $<100 \mathrm{ppm}$ & $0.31-0.42$ & $0.13-0.19$ \\
\hline $700-800$ & $820-920$ & No & 3 & 6 & $0.06-0.10$ & $1.50-1.90$ & $<0.018$ & $<0.010$ & $<0.05$ & Res & Res & Res & $0.10-0.20^{(5)}$ & Res & $0.060-0.070$ & $<0.030$ & $0.090-0.100$ & $<60 \mathrm{ppm}^{(6)}$ & $0.34-0.46$ & $0.14-0.21$ \\
\hline $700-800$ & $820-920$ & No & 6 & 12 & $0.06-0.10$ & $1.50-1.90$ & $<0.018$ & $<0.010$ & $<0.05$ & Res & Res & Res & $0.10-0.20^{(5)}$ & Res & $0.060-0.070$ & $<0.030$ & $0.090-0.100$ & $<60 \mathrm{ppm}^{(6)}$ & $0.34-0.46$ & $0.14-0.21$ \\
\hline $700-800$ & $820-920$ & -20 & 3 & 6 & $0.06-0.10$ & $1.50-1.90$ & $<0.018$ & $<0.010$ & $<0.05$ & Res & Res & Res & $0.10-0.20^{(5)}$ & Res & $0.060-0.070$ & $<0.030$ & $0.090-0.100$ & $<60 \mathrm{ppm}^{(6)}$ & $0.34-0.46$ & $0.14-0.21$ \\
\hline $700-800$ & $820-920$ & -20 & 6 & 12 & $0.06-0.10$ & $1.50-1.90$ & $<0.018$ & $<0.010$ & $<0.05$ & Res & Res & Res & $0.10-0.20^{(5)}$ & Res & $0.060-0.070$ & $<0.030$ & $0.090-0.100$ & $<60 \mathrm{ppm}^{(6)}$ & $0.34-0.46$ & $0.14-0.21$ \\
\hline Notes: & & & & & & & & & & & & & & & & & & & & \\
\hline 1 & Si is typci & ally $<0.05$, & but can b & $p$ to 0.3 & $30 \%$ for sc & ome struc & ctural gr & ades & & & & & & & & & & & & \\
\hline 2 & N2 will va & ary from $E A$ & $\mathrm{~F}$ to $\mathrm{BOF}$ & may b & e $>100 p$ & opm depe & ending or & n facility & & & & & & & & & & & & \\
\hline 3 & Ti can be & used as nee & eded to & trol N2 & and $\mathrm{Nbs}$ & solubility & & & & & & & & & & & & & & \\
\hline 4 & Ti should & be used to & control & and $\mathrm{Nb}$ & solubilit & & & & & & & & & & & & & & & \\
\hline 5 & Moly may & or may no & t be use & pendin & ng on TS & and micrc & ostructur & re contrc & l capa & lities & & & & & & & & & & \\
\hline 6 & Recomme & eneded N2 & for optir & n Ti effi & iciency & & & & & & & & & & & & & & & \\
\hline 7 & Nb levels & may need & tro be ac & ted up & to contrc & ol the pro & per amo & ount of $T$ & ype II & -recyr & allizat & in beh & avior and $n$ & ninimiz & e dynamic $r$ & ecrystall & Ilization fron & m occuring & & \\
\hline & & & additior & $b$ maxir & mum lev & vels may b & be driver & n by soci & etal m & imum & & & & & & & & & & \\
\hline 8 & Ti may be & able to be & reduced & he tota & al amoun & t of Type & II No-re & crystalli & zation & havior & $s>65 \%$ & hrougt & proper $\mathrm{N}$ & $b$ metal & |lurgy & & & & & \\
\hline 9 & $\mathrm{Nb}$ level $\mathrm{r}$ & may need $t$ & to go high & up to 0. & $.070 \%$ if & societal s & tandards & s will all & & & & & & & & & & & & \\
\hline 10 & Mn may $\mathrm{h}$ & lave to be a & adjusted & ed on $t$ & the actua & al or purp & oseful ac & ddiitnos & of $\mathrm{Cu}$, & , Cran & Mo & & & & & & & & & \\
\hline 11 & FeV addit & tion upto 0 . & $.050 \% \mathrm{me}$ & e need & led for TS & & & & & & & & & & & & & & & \\
\hline 12 & Based on & $\mathrm{Cu}, \mathrm{Ni}, \mathrm{Cr}$, & residual & des of 0 & 0.02 , resi & idual Mo c & of $0.01 \mathrm{ur}$ & Inless ad & ded, Si & $f 0.02$ & d 0.05 & & & & & & & & & \\
\hline 13 & CE -Deard & den/O'Neil & formula, & $\mathrm{Mn} / 6+1$ & $(\mathrm{Cu}+\mathrm{Ni}) / 1$ & $15+(\mathrm{Cr}+\mathrm{M}$ & $(0+V) / 5$ & & & & & & & & & & & & & \\
\hline 14 & Pcm - Ito/ & /Bessyo, C & $+\mathrm{Si} / 30+(\mathrm{I}$ & $\mathrm{Cu}+\mathrm{Cr})$ & $/ 20+\mathrm{Ni} / 6$ & $60+\mathrm{Mo} / 15$ & $+V / 10+B$ & & & & & & & & & & & & & \\
\hline
\end{tabular}

\section{STEELMAKING/CASTING}

A key parameter in steelmaking is oxygen control. Ideally total oxygen should be kept $\leq 20 \mathrm{ppm}$. The various oxides formed from excessive oxygen can contribute to slab surface quality issues such as pinhole/porosity and transverse cracking issues. In 
addition the slab internal cleanliness is affected by excessive oxygen which negatively affects ductility (toughness/formability).

A good quality slab is required to produce a good quality, cost effective hot strip structural coil. The alloy guidelines shown in Table 2 are designed to not only to contribute to the overall cost effectiveness of the product, but to assist in producing a quality cast slab. The low carbon content, control of aluminum along with proper $\mathrm{Nb} / \mathrm{Ti}$ use are key points to minimizing of both external and internal slab quality issues such as cracking (longitudinal/transverse), internal cleanliness and centerline alloy segregation that results in final undesired as-rolled microstructural banding. However, alloy alone is not the only parameter to control for good external and internal slab quality. Casting processing parameters along with the alloy design are very much an integral part of producing cost effective high quality structural steel slabs.

\subsection{External Slab Quality Issues/Controls}

There are only five main types of external slab quality issues that create surface quality issues in hot strip structural steel coil [6]. In order of frequency/priority is as follows:

1. Porosity/pinholes - this is the \#1 problem, in spite of what many think.

2. Cracking - this is the \#2 problem

a. Longitudinal, b. Transverse, c. Star Cracks

3. Deep Oscillation Marks

4. Poor Scarfing Technique/Control

5. Mechanical Mold Wall Contamination, Scratches, Gouges, Etc.

Examples of the five slab quality issues and resultant hot strip coil issue can be seen in Figure $2[7,8]$.
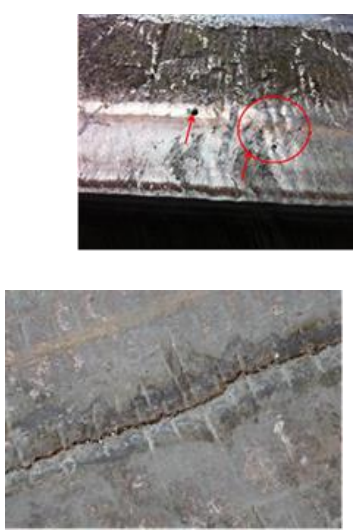

Longitudinal Cracking and resultant defect

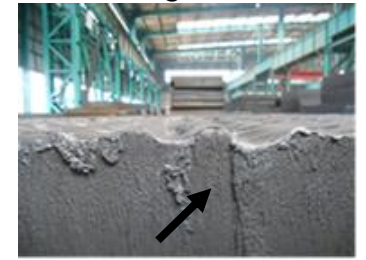

Poor Scarfing

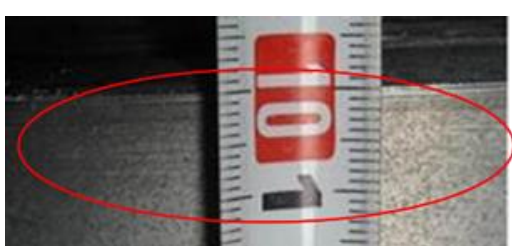

Pinholes/ Porosity and resultant defect
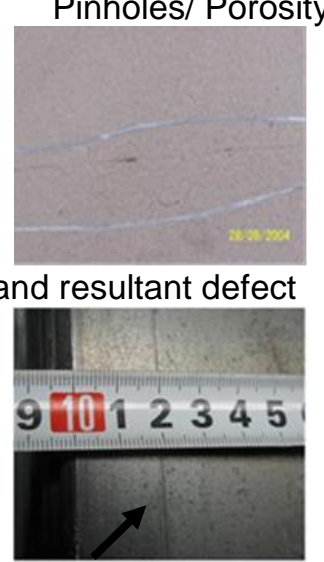

Figure 2. Examples of typical slab external quality issues and corresponding hot strip surface defects

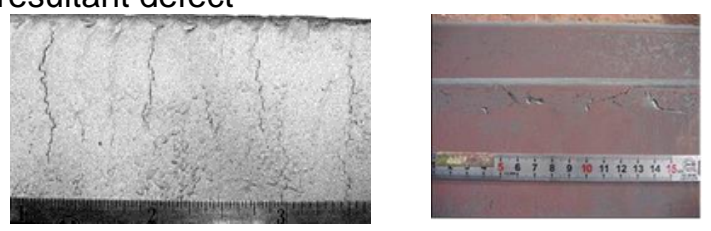

Transverse Cracking and resultant defect

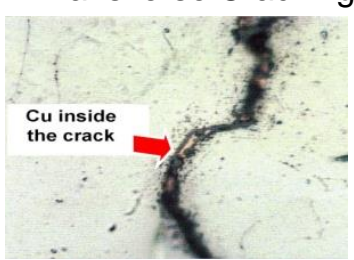

Copper Mold Wall Contamination

Casting parameters that must be controlled to minimize or eliminate the formation of these typical external slab defects are as follows: 
1. Total gas content $(\mathrm{Ar}, \mathbf{O} 2, \mathbf{N} 2, \mathbf{H 2})$.When the sum of $\mathrm{Ar}+\mathrm{CO}+\mathrm{N} 2+\mathrm{H} 2>1$ atm @ $90 \%$ solidification pinholes/porosity can form. The use of vacuum degassing has shown a significant influence in the reduction of pinholes, porosity and blowholes in hot strips coils microalloyed with $\mathrm{Ti}$ and $\mathrm{Nb}$ [10].

2. Maximum average superheat $-<25^{\circ} \mathrm{C}$. Aluminum killed steels with $\mathrm{C}<0.10 \%$ and $\mathrm{Mn}<0.80 \%$ with low superheat tend to have clogging at the end of the heats. In this case continuous temperature measurement device of steel in the tundish is recommended to prevent interruption of the casting sequence.

3. Proper casting speed/strain rate for the slab width, typically between 0.9-1.2 $\mathrm{m} / \mathrm{min}$ depending on thickness and width. In the continuous casting of flat products, the corners cool faster than the four surfaces of the slab. This is particularly a problem when the corner temperatures reach the range of low ductility (750-925 ${ }^{\circ} \mathrm{C}$ ) which causes fragility of these corner regions, and hence there is a greater probability of generating surface defects during the slab straightening. In this condition casting, caused when the casting speed is low, transverse cracks corner are formed in the bottom of oscillation marks on the corner of the slab due to stress concentration, and propagate during the straightening process reaching up to $20 \mathrm{~mm}$ of length. Microalloyed $(\mathrm{V} / \mathrm{Nb} / \mathrm{Ti})$ high strength steels are particularly prone to develop this type of cracking. The application of alternative geometries, such as chamfered corners, of continuous casting molds has a significant influence on the reduction in the formation of cracks in the slabs. Unlike conventional slab geometry, without chamfer, the corners where heat is extracted from two surfaces perpendicular to both, the bevel geometry enables a substantially uniform heat extraction because the heat is removed only in the tangential surface. Thus, it is possible to maintain the corners temperature above low ductility temperature during slab straightening process and prevent the occurrence of transverse cracks corner. Additionally, the larger corner angle reduces of the stress concentration at the bottom of the oscillation marks on the corner of the slab and also shows advantages during the rolling process. Modified mold geometry has shown a significant reduction of cracks at various steel facilities in the world [11,12].

4. Mold level control, should be $< \pm 5 \mathrm{~mm}$. Accurate mold level control, 2 sigma better than $+/-5 \mathrm{~mm}$ and usually better than $+/-3 \mathrm{~mm}$ for $95 \%$ of measurements. Poor level control gives uneven and sometimes overlapping oscillation marks. It has been shown a linear growth of longitudinal cracks with mold level variations greater than $5 \mathrm{~mm}$ [17].

5. Excessive narrow face taper, should be $<1.2 \% / \mathrm{m}$

6. Oscillation frequency. A short negative strip time (NST) is usually associated with shallow oscillation marks, which are important for good surface quality. Hydraulic oscillation allow non-sinusoidal waveforms to be readily generated. This oscillation mode offers the ability to achieve adequate mold flux feeding with less dependence on NST. Non-sinusoidal oscillation allows casting with the same NST over the entire speed range preventing the occurrence of deep oscillation marks at low casting speeds reducing transverse cracks.

7. Proper mold powder formulation for carbon content and casting speed. Besides ensuring the continuous and uniform feeding, the flux film between the slab and the copper plate should carry out the lubricant functions and heat extraction driver during the casting. The peritectic microalloyed steels have been most successful cast with high basicity fluxes $(\mathrm{CaO} / \mathrm{SiO} 2>1.3)$. 
8. Critical surface temperatures. One consideration for selection of cooling regime is the surface temperature of the strand at straightening. Microalloyed ( $\mathrm{Nb} / \mathrm{V} / \mathrm{Ti})$ steels have a ductility trough, which varies according to steel composition but typically is worst between $750-925^{\circ} \mathrm{C}$. To straighten with the surface temperature in this region would risk surface cracks due to the straightening strains applied - typically transverse corner cracks. It is necessary for these steel grades to avoid this temperature region. For smaller radius bow type casters it is best to achieve this aim using "soft" cooling strategies. For large radius machines on the other hand, where there is a large distance between mold and straightener, then there is a better chance of avoiding the ductility trough using "hard" cooling strategies

9. Secondary cooling water strategy, Figure 3. The secondary cooling strategy is very important to minimize transverse cracking. In microalloyed steels, if

slab straightening is carried out within a ductility trough, transverse cracking can result. If slab straightening is carries out at temperatures either above or below this temperature range $\left(750^{\circ} \mathrm{C}-925^{\circ} \mathrm{C}\right)$, cracking should be minimized. Both cooling strategies ("soft" cooling and "hard" cooling) have been used on various machines with success in reducing cracking. When a "soft" cooling strategy is used, it is important to keep the entire cross section of the slab above the critical temperature, including the slab corners, which are typically colder than the broad face. This has encouraged the installation of devices to maintain a high temperature in the slab corner region in some plants. A steep temperature gradient through the slab thickness is also desirable using this cooling strategy, to minimize the penetration of surface cracks which may form in cold spots. For "hard" cooling strategies, it is important to maintain all cooling nozzles; blocked cooling nozzles may lead to localized regions of the slab having temperatures within the critical range. A "hard" cooling strategy may also lead to subsurface crack formation: the distance between these cracks and the slab surface must be such that they are not exposed during subsequent reheating operations. "Hard" cooling practices may also increase thermal stresses.

10. Control of Al, S, P and N2, $\mathbf{O} 2$ inclusion formation/frequency. There have been a number of investigations about the influence of aluminum $(\mathrm{Al})$ and nitrogen $(\mathrm{N})$ on hot ductility. Increasing either the $\mathrm{Al}$ or $\mathrm{N}$ levels leads to a deterioration in hot ductility. It was shown that the product of [sol. $\quad \mathrm{Al}] \mathrm{x}[\mathrm{N}]$ is important in controlling ductility regardless of whether it is $\mathrm{N}$ or $\mathrm{Al}$ that is high. For higher manganese steels (i.e.1.40\% Mn), the product of [sol. Al] $\times[\mathrm{N}]$ had to approach $2 \times 10^{-4} \quad$ (i.e. $0.040 \% \mathrm{Al}, 0.005 \% \mathrm{~N}$ ) for precipitation to occur. When temperature oscillations are introduced, AIN precipitation occurs even in low $\mathrm{Al} / \mathrm{N}$ steels, even for values as low as $1 \times 10^{-4}$ (e.g. $0.020 \% \mathrm{Al}$ and $0.0050 \% \mathrm{~N}$ ). Therefore, it is recommended that aluminum and nitrogen levels be kept low to avoid transverse cracks. Correlations between [sol. Al] $\times[\mathrm{N}]$ and the occurrence of transverse cracks in slabs was raised showing that there is an exponential growth in rejection rates for HSLA and API steels for [sol. Al] x [N] greater than 2 $x 10^{-4}$. Commercial steel grades, like ASTM A36, are also prone to transverse cracks when the product [sol. Al] $\times[\mathrm{N}]$ is above $3 \times 10^{-4}$ [15].

11. Casting water temperature too hot, $>27^{\circ} \mathrm{C}$, Figure 3

12. Machine alignment/maintenance

a. Improper segment gaps, should be $< \pm 0.5 \mathrm{~mm}$

b. Alignment issues, should be $<0.5 \mathrm{~mm}$

13. Proper mold coating to avoid copper contamination. 


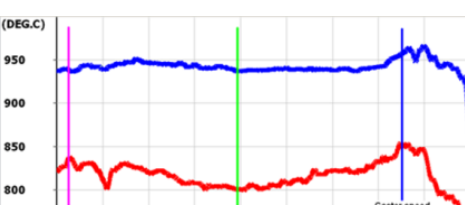

Slab corner temperature (red line) vs. slab body temperature (blue line) in the unbending zone, slowing cast speed from $0.9 \mathrm{~m} / \mathrm{min}$ to 0.8 $\mathrm{m} / \mathrm{min}$ (pink to green line) and then speeding back up to 0.9 $\mathrm{m} / \mathrm{min}$ (green line to blue line)
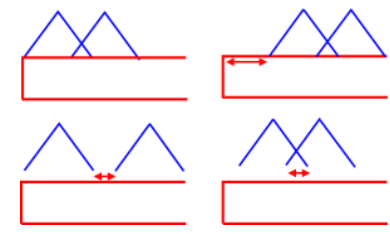

Example of various secondary cooling water strategies to control temperature.

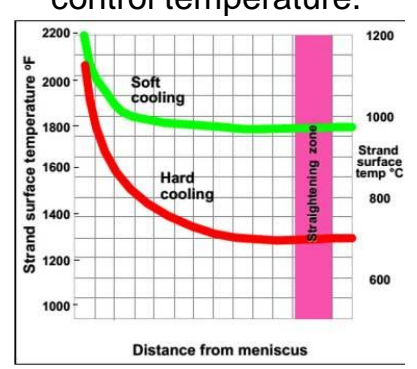

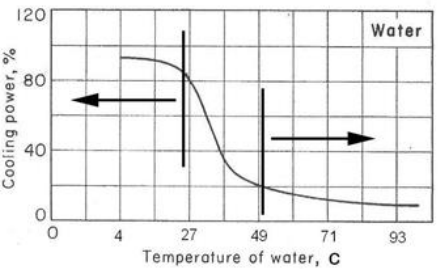

Effect of water temperature on the efficiency of the water to extract heat. Note the step change in heat extraction efficiency between $27-49^{\circ} \mathrm{C}$.

Figure 3. Examples of casting speed, secondary cooling strategies and water temperature

\subsection{Internal Slab Quality Issues/Controls}

There are only two key points in regard to internal slab quality that can cause issues in the production of hot strip structural steel coils.

1. Centerline alloy segregation

2. Inclusion size and frequency: we are not trying to produce "inclusion free" steel, but we are trying to minimize the inclusion sizes and frequency.

A slab macroetch, not a sulfur print due to the low carbon content, is the best method to gauge the internal centerline alloy segregation. The international standard for slab centerline alloy segregation is the Mannesmann Center Segregation Core Unsoundness rating system of 1-5 (1 best, 5 worst), Figure 4 [9]. Figure 5 shows an actual low carbon, $<0.10 \%$, slab macroetch using a modified Mannesmann rating scale of half increments.

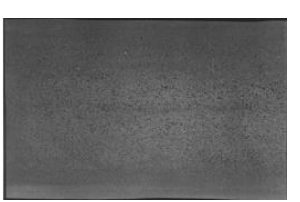

Class 1

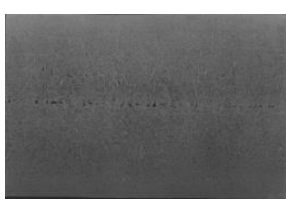

Class 2

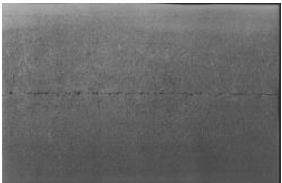

Class 3

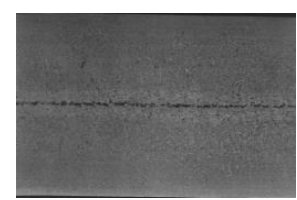

Class 4

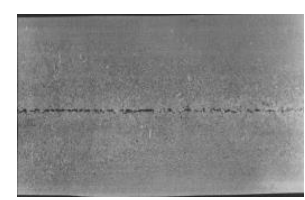

Class 5

Figure 4. Mannesmann Center Segregation Core Unsoundness Rating System for Slab Quality

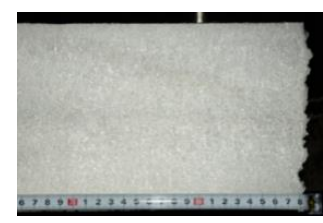

Class 1

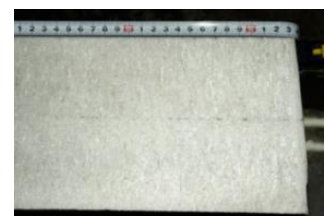

Class 1.5

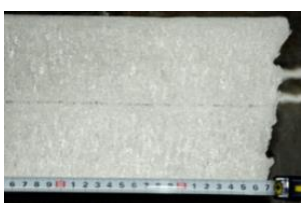

Class 2

Figure 5. Example of slab macroetch of low carbon, $<0.10 \%$, using Mannesmann modified half increment rating scale for center segregation core unsoundness

If the center alloy segregation is not controlled properly then the resultant rolled transformed microstructure becomes banded, Figure 6, which will lower overall ductility (elongation, formability and toughness). 


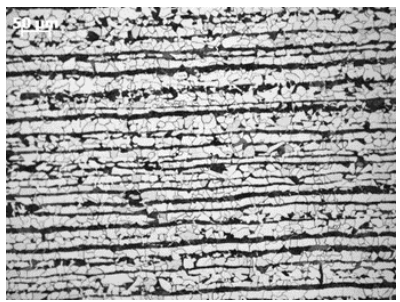

High strength $690 \mathrm{MPa}, \mathrm{C}, 0.10 \%, \mathrm{Mn}-1.80 \%$, center thickness

Low strength $355 \mathrm{MPa}, \mathrm{C}>0.10<0.15 \%, \mathrm{Mn}$ $1.10-1.30 \%$, center thickness

Figure 6. Microstructural banding from poor slab center alloy segregation alloy/process control

The elements that segregate at the highest concentration in order of severity are:

\section{Carbon, 2. Phosphorus, 3. Sulfur, 4. Silicon, 5. Manganese}

As can be seen, the alloy designs presented purposely control carbon, phosphorus, sulfur and silicon to low levels and use only the necessary amount of manganese for strength to assist in minimizing creating unnecessary center alloy segregation.

As in the external slab quality optimization, internal slab quality is also a combination of not only alloy design, but proper process control on the caster. Key processing parameters to control, which many are the same as what is needed for good external slab quality, are as follows:

1. Maximum average superheat $-<25^{\circ} \mathrm{C}$, preferably $<20^{\circ} \mathrm{C}$.

2. Proper casting speed, $<1.3 \mathrm{~m} / \mathrm{min}$ (slab thickness/width dependent). Variations in centerline segregation has been shown with various combinations of casting speed and superheat. Casting at lower superheats had less centerline segregation, while increasing casting speed resulted in increased amounts of centerline segregation. In addition, large variability in centerline segregation has been observed at any given casting speed. This indicates that other factors, such as roll and spray nozzle conditions, can also influence the extent of centerline segregation, Figure $7[15,16]$.

3.
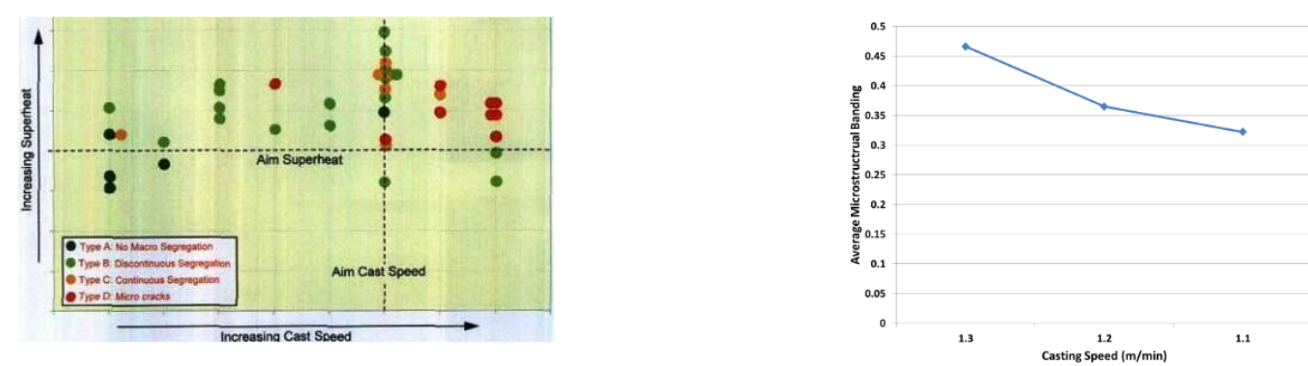

Figure 7. Centerline segregation variation with casting speed and superheat, left figure. Right figure, casting speed vs. ASTM average microstructural banding rating for a low carbon, $<0.05 \%$. The slower casting speed improves the slab center alloy segregation which in turn improves the final transformed microstructural banding.

\section{Proper mold powder formulation}

5. Secondary cooling water strategy, water temperature and flow, sometimes called "cooling intensity" as discussed prior.

6. Casting water temperature control, same issues as discussed prior and seen in Figure 3. 
7. Proper segment roll gap settings, $\pm 5 \mathrm{~mm}$ maximum

8. Proper use of soft reduction, if available

9. Proper use of electromagnetic stirring (EMS), if available

10. Machine alignment/maintenance, same as for external slab quality parameters

\subsection{Miscellaneous}

In the high strength steels, $>600 \mathrm{MPa}$ yield strength, that utilize titanium precipitation strengthening mechanisms hot/warm charging should be used for reheating. Allowing these alloy grades to cool in slab form and then reheating from ambient temperature will result in the corners of the slabs to crack during reheating, Figure 8 [17]. The ascast structure along with the volume fraction of overall precipitates formed make these slabs sensitive thermal expansion in the temperature range of ambient to $300^{\circ} \mathrm{C}$, especially the slab corners which experience three sided heating and hence higher thermal expansion rates. While the thermal expansion rate of the slab corners are the same as the lower strength alloy designs, the addition of the volume fraction of titanium precipitates further weakens the as-cast structures ability to withstand the stress of the thermal expansion volume change.
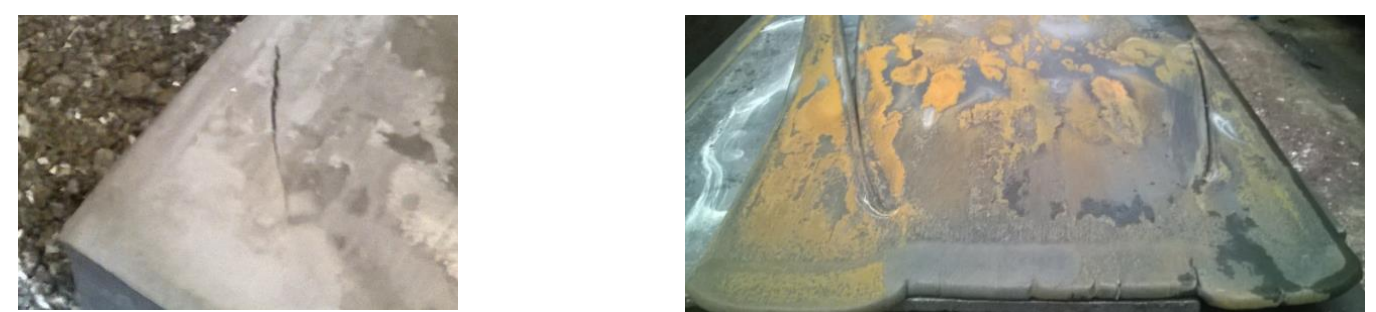

Figure 8. Example of slab thermal expansion corner cracking of $690 \mathrm{Mpa}$ yield strength titanium precipitation strengthening grades. Slab corner after reheating, rolled slab after roughing.

\section{CONCLUSION}

Proper cost effective metallurgical strategy, alloy design and key steelmaking/casting parameters for the production of hot strip structural steel coil from $300-700 \mathrm{MPa}$ yield strength have been discussed. Microstructure and cross sectional grain size/distribution are the starting considerations points that drive the alloy/process design. Proper control of steelmaking and casting parameters utilizing the optimum alloy designs presented can result in cost effective high quality structural steel coil that can be technically marketed to meet the demanding mechanical property requirements in today's market.

\section{REFERENCES}

1 Stalheim, D, Basic Concept of Increased Strength and Toughness of Structural Long Products Utilizing Niobium Microalloy Technology, Long Products Seminar Presentation, CIT-SENAI, Belo Horizonte, Brazil, 2015.

2 Lu J, Ivey D, Henein H, Wiskel J, Omotoso O, Microstructure Characterization and Strengthening Mechanisms of Microalloyed Steels, Proceedings of $7^{\text {th }}$ ASME International Pipeline Conference, Calgary Canada, 2008.

3 Stalheim, D, DGS Recrystallization Behavior Analysis and Summary, DGS Metallurgical Solutions, Inc. Internal Training Presentation, 2015.

4 Samuel F, Barbosa R, Boratto F, Yue S, Jonas J, Laboratory Simulation of Flow Stresses during Strip Rolling Using High Strain Rate Torsion Testing, Proceedings 
International Conference on Physical Metallurgy of Thermomechanical Processing of Steels and Other Metals (Thermec 88), Tokyo, Japan, June, 1988.

5 Stalheim, D, Recrystallization Behaviors in the Production of Structural Steels, Proceedings of ABM 52 ${ }^{\text {nd }}$ Rolling Seminar, Brazil, 2015.

6 Stalheim, D, Identification and Investigation of Continuous Cast Slab and Billet Defects, Roundtable Meeting on the Quality Control of Billets, Slabs and Beams of Nb-bearing Steels, CITIC/CBMM, Beijing, China, 2009.

7 Jansto, S, Continuous Casting Course, 46 ${ }^{\text {th }}$ ABM Steelmaking, Brazil, 2015.

8 Stalheim, D, Optimized Production of Niobium Microalloyed Slabs, Plates and Coil, Proceedings of SimPro16, India, 2016.

9 SMS Siemag, Classification of defects in materials, Standard charts and sample guide, SN960, 2010.

10 Suzaki et. al, Evolução dos processos de refino e lingotamento de aços microligados e tratados com CaSi na CSN: controle de inclusões e porosidades, XXXVI Seminário de Fusão, Refino e Solidificação dos Metais da ABM, Vitória-ES, Maio 2005.

11 Ramstorfer et.al., Melhoria da Qualidade do Produto através da Aplicação de uma Geometria de Molde Chanfrada, 46은 Seminário de Aciaria - Internacional, ABM Week, Agosto de 2015, Rio de Janeiro - RJ, Brasil.

12 Ma Shuo et. al., Discussion for what Role Corner Cross Cracks Play in Side Defects on Hot Coil, The 10th CSM Steel Congress \& The 6th Baosteel Biennial Academic Conference, October 2015, Shanghai, China.

13 Guzela et. al., Nitrogen Control in Continuous Casting for High Strength Microalloyed Steels, The 10th CSM Steel Congress \& The 6th Baosteel Biennial Academic Conference, October 2015, Shanghai, China.

14 Sengupta et. al., Qualitative and Quantitative Techniques for Evaluating Manganese Segregation in Advanced High-Strength Steels at ArcelorMital Dofasco's no 1 Continuous Caster, Iron \& Steel Technology, page 70, October 2011.

15 Stalheim, D, Production of API HIC Steels for Sour Service Oil and Gas Transmission Pipelines, Proceedings of MS\&T 2012, USA, 2012.

16 Ushijima et. al., Instrumentation and Control System on Recent Continuous Casting, Tetsu-to-Hagane Vol.67, 1981, n־8, page 1056.

17 Stalheim, D, Proper Reheating of High Titanium Slabs, Internal Report DGS Metallurgical Solutions, Inc., 2015. 